\title{
Adverse childhood experiences and child mental health: an electronic birth cohort study
}

Emily Lowthian ${ }^{1,2^{*}}$ (D), Rebecca Anthony ${ }^{2,3}$, Annette Evans ${ }^{4}$, Rhian Daniel ${ }^{4}$, Sara Long ${ }^{2}$, Amrita Bandyopadhyay ${ }^{5}$, Ann John ${ }^{1,3}$, Mark A. Bellis ${ }^{6}$ and Shantini Paranjothy ${ }^{7}$

\begin{abstract}
Background: Adverse childhood experiences (ACEs) are negatively associated with a range of child health outcomes. In this study, we explored associations between five individual ACEs and child mental health diagnoses or symptoms. ACEs included living with someone who had an alcohol-related problem, common mental health disorder or serious mental illness, or experienced victimisation or death of a household member.

Methods: We analysed data from a population-level electronic cohort of children in Wales, UK, $(N=191,035)$ between the years of 1998 and 2012. We used Cox regression with discrete time-varying exposure variables to model time to child mental health diagnosis during the first 15 years of life. Child mental health diagnoses include five categories: (i) externalising symptoms (anti-social behaviour), (ii) internalising symptoms (stress, anxiety, depression), (iii) developmental delay (e.g. learning disability), (iv) other (e.g. eating disorder, personality disorders), and (v) any mental health diagnosis, which was created by combining externalising symptoms, internalising symptoms and other. Our analyses were adjusted for social deprivation and perinatal risk factors.

Results: There were strong univariable associations between the five individual ACEs, sociodemographic and perinatal factors (e.g. gestational weight at birth) and an increased risk of child mental health diagnoses. After adjusting for sociodemographic and perinatal aspects, there was a remaining conditional increased risk of any child mental health diagnosis, associated with victimisation (conditional hazard ratio (cHR) 1.90, Cl 95\% 1.34-2.69), and living with an adult with a common mental health diagnosis (CHR 1.63, Cl 95\% 1.52-1.75). Coefficients of product terms between ACEs and deprivation were not statistically significant.
\end{abstract}

\footnotetext{
* Correspondence: e.m.lowthian@swansea.ac.uk

${ }^{1}$ Population Data Science, Swansea University Medical School, Singleton Park, Swansea SA2 8PP, UK

2DECIPHer, 1 - 3 Museum Place, School of Social Sciences, Cardiff University, Cardiff CF10 3BD, UK

Full list of author information is available at the end of the article
}

(c) The Author(s). 2021 Open Access This article is licensed under a Creative Commons Attribution 4.0 International License, which permits use, sharing, adaptation, distribution and reproduction in any medium or format, as long as you give appropriate credit to the original author(s) and the source, provide a link to the Creative Commons licence, and indicate if changes were made. The images or other third party material in this article are included in the article's Creative Commons licence, unless indicated otherwise in a credit line to the material. If material is not included in the article's Creative Commons licence and your intended use is not permitted by statutory regulation or exceeds the permitted use, you will need to obtain permission directly from the copyright holder. To view a copy of this licence, visit http://creativecommons.org/licenses/by/4.0/. The Creative Commons Public Domain Dedication waiver (http://creativecommons.org/publicdomain/zero/1.0/) applies to the data made available in this article, unless otherwise stated in a credit line to the data. 
Conclusion: The increased risk of child mental health diagnosis associated with victimisation, or exposure to common mental health diagnoses, and alcohol problems in the household supports the need for policy measures and intervention strategies for children and their families.

Keywords: Adverse childhood experiences, Mental health, Cohort, Wales, Survival analysis, Administrative data

\section{Background}

It is well established that adverse childhood experiences (ACEs), such as abuse, neglect and household dysfunction, are negatively associated with numerous physical, social, emotional and behavioural problems in adulthood [1-3]. Up to two thirds of the population experience at least one ACE before the age of eighteen, and one quarter experience four or more [4]. Since the initial suggestion that the association between ACEs and poor outcomes was due to maladaptive coping mechanisms (e.g. substance abuse), we have seen the emergence and debate of additional mechanisms such as epigenetic and neurobiological processes that affect the development of the brain and endocrine systems $[5,6]$.

Childhood mental health diagnoses are relatively common, with prevalence rates being around $10 \%$ of children between the ages of 5 and 16 [7]. Understanding the relationship between exposure to ACEs and children's behavioural and psychological outcomes is important as psychological disorders in childhood or adolescence are strong predictors of psychiatric disorders in adulthood [8]. A systematic review of empirical research on the association between ACEs and child developmental wellbeing [9] reported an association between cumulative ACEs (a count of exposures) and child behavioural problems; however, it was limited by the small number of studies, most of which included high-risk individuals (e.g. from populations receiving child welfare).

To date, ACEs have largely been examined cumulatively, and while useful, this has led to a limited understanding of which ACEs are the greatest risk for child mental health, and their relative contributions $[10,11]$. The overarching literature suggests that victimisation tends to be a greater risk for internalising symptoms, and household dysfunction a larger risk for externalising symptoms [11-13]. Moreover, Hussong et al. (2007) documents that children of alcoholics are at risk for externalising symptoms, but less so for internalising symptoms [14, 15]. In terms of developmental delay, Ouyang et al. (2008) found an association between maltreatment, which included neglect and abuse, and attention-deficit disorders [16]. One study examined multiple ACEs measured individually and found that abuse, neglect, household mental illness or substance use was related to childhood depressive symptoms [10]. Due to the vast literature across areas of mental health focusing on cumulative or only one or two ACEs, there is a need to examine the risks that multiple individual ACEs pose for child mental health outcomes.

Moreover, mental health diagnoses are socially patterned, with higher rates observed among those with lower socioeconomic status or who live in areas with higher levels of social deprivation [17, 18]. Reiss (2013) conducted a systematic review and found that 52 of the 55 studies identified confirmed this relationship. They found that children from disadvantaged families were approximately two to three times more likely to develop mental health disorders. Some theoretical explanations include the social causation hypothesis, which suggests that stress associated with a low social position contributes to the development of mental health disorders [18]. This, paired with the knowledge that children from disadvantaged backgrounds are much more likely to experience an ACE [2], raises the question as to the role of ACEs in the relationship between social disadvantage and mental health outcomes. However, little research has addressed this, and it is considered a significant gap in the field $[19,20]$.

In this study, we address the gap in the evidence base in four ways. First, we assess the associations between individual ACEs, demographic and perinatal confounders on the rate of child mental health diagnoses and symptoms using univariable models. Second, in a single model, we investigate the conditional association of all demographic and perinatal confounders with the rate of child mental health outcomes. Third, we investigate the extent to which the conditional associations of the demographic and perinatal variables with child mental health outcomes change upon adding the individual $\mathrm{ACE}$ variables into the previous model. Lastly, we investigate the extent to which the available measure of deprivation moderates the associations found between individual ACEs and child mental health outcomes. The four steps are ultimately motivated by a desire to understand the effects of ACEs individually (as opposed to cumulatively) on child mental health (step 3), the extent to which these are confounded by sociodemographic factors (comparing steps 1 and 3) and the extent to which they are moderated by deprivation (step 4). Additionally, we are interested in the extent to which the five ACEs mediate the effect of sociodemographic factors on child mental health, which we will assess informally by comparing steps 2 and 3, rather than conducting a formal mediation analyis. 


\section{Methods}

\section{Data sources and study design}

The Wales Electronic Cohort for Children (WECC) contains 981,404 children born between Jan 1, 1990, and Oct 7, 2012, for a child or mother resident in Wales [21]. WECC is derived from de-identified routinely available health and social data sets that have been recordlinked and made available, to protect privacy, in the Secure Anonymised Information Linkage (SAIL) databank at Swansea University, UK [22, 23]. Individuals are allocated a unique Anonymised Linking Field based on encrypted National Health Service numbers provided by NHS Wales Informatics Service (NWIS), for each data set within the SAIL databank. The SAIL linkage system uses a both deterministic and probabilistic recordlinkage with more than $99.9 \%$ accuracy. Deterministic record-linkage is based on NHS numbers and probabilistic record-linkage based on first name, surname, date of birth, gender and phonetic and soundex version of names [23]. Each child was assigned a residential anonymised linking field (RALFs) for each address during the study period, created by encrypting addresses within NWIS [24, 25], which enables anonymous linkage of those living in the same household. We used WECC data from Jan 5, 1998, to Oct 7, 2012, and this was defined by the availability of data on hospital admissions from the Patient Episode Database for Wales. This enabled measurement of ACE exposures using hospital admission and primary care data for each child, and household members that a child lived with. Each child also had perinatal variables using data from the National Community Child Health Database and outcome measures using General Practice (GP) data from Welsh Longitudinal General Practice data set. We included children who were living in Wales, for whom GP data were available. Children who had moved away or died were censored on the date they moved out of Wales (identified from the Wales Demographic Service) or died (identified from the Public Health mortality files) before Oct 12, 2012. Children were included if they had a valid RALF and adult household members with sufficient primary care data to enable ascertainment of exposure groups (See Figure 1 in Additional file 1 for participant flowchart). At the time of data extraction, the SAIL databank had data from over $40 \%$ of the 474 General Practices in Wales, over 1.9 million people.

\section{Measures}

\section{Adverse childhood experiences (ACEs)}

As in other research [26], we defined five measures of ACEs. The first relates to childhood victimisation, defined using a set of ICD-10 codes in any position of a finished consultant episode of an inpatient hospital admission [27]; we did not use $\mathrm{P}$ codes as these are neonatal related, for codes see Additional file 13, Table 11. Three further ACEs relate to household dysfunction and were defined as the presence of any of the following in an adult household member: (i) serious mental illness diagnosis (e.g. bipolar, schizophrenia) [28], (ii) common mental disorder (e.g. depression, anxiety) [29] and (iii) problematic alcohol use ascertained using a set of primary care READ codes for heavy drinker, ex-heavy drinker, alcohol dependence, alcoholic liver disease, alcohol related nervous system or stomach problems, poisoning or treatment evidence [30] and/or any alcoholrelated emergency hospital admission during the exposure period [31]. The fifth ACE was the date of death of a household member, given that the loss of a parent, sibling or other non-parent household member is likely to be a momentous event [32].

Household members were defined as those who were living in the same household as the child on their on their 1st, 5th or 8th birthday. For household members who were living with the child on their first birthday, we also ascertained if there was any history of a common mental disorder or serious mental illness from 1998 onwards. We created four exposure periods: birth to $<1$ year, $1 \leq 5$ years, $5 \leq 8$ years and $8 \leq 12$ years. The presence or absence of each of the five ACEs as defined above, in each exposure period, was ascertained from a search for the relevant READ or ICD-10 codes for any adult that was living with the child on their 1st, 5th, 8th or 12th birthday. We assigned a date of exposure that corresponded with the end date in each exposure period, so that the analysis could take account of the temporal relationship between exposure and outcome.

\section{Outcome measures}

We categorised READ codes (from primary care GP data) relevant to child mental health diagnoses in to four categories: (i) externalising symptoms (anti-social behaviour), (ii) internalising symptoms (stress, anxiety, depression), (iii) developmental delay (learning disabilities, attention deficit) and (iv) other (e.g. eating disorders, personality disorders). A fifth outcome of any mental health was created using the categories of externalising, internalising symptoms and other, but not developmental delay. See Additional files 11 and 12, Tables 9 and 10 for all READ codes for each category.

\section{Covariates}

A directed acyclic graph (DAG) [33] was drawn to visualise plausible confounding relationships and to choose a suitable set of potential confounders for analyses (see Figure 2 in Additional file 2). Based on the DAG, we adjusted for the child's sex, young maternal age $(<18$ years), small-area deprivation (based on Townsend score [34], using the 2001 census for income and address), 
single adult household, and perinatal factors including gestational age at birth, small for gestational age, twins or triplets, maternal smoking during pregnancy, parity, birthweight, congenital abnormalities and breastfeeding at birth or at 6-8 weeks.

\section{Statistical analysis}

We used Cox proportional hazards regression models throughout, with the outcome defined as the time to the first child mental health diagnosis or symptoms as recorded by the GP. When including demographic and perinatal variables as predictors in these models, they are entered as time-fixed covariates at birth. When the five individual ACE exposure variables are included, these are discrete and time-varying, taking the value 0 until the first exposure, and 1 thereafter.

The occurrence of missing data was low (between 0\% and 3.7\%) for most variables. However, breastfeeding and maternal smoking had notably higher prevalence of missing data (13.2\% and 65\%, respectively); organisational and administrative differences between hospitals and data collation may explain why maternal smoking has a high proportion of missing data. The subset for which data were available was large enough to fit an imputation model for these covariates with sufficient precision. Stata IC was used for statistical analyses and multiple imputation [35]. We used multiple imputation with chained equations (MICE) to account for missing data under the missing at random assumption [36]; five imputations were conducted. The imputation model included all covariates, an event indicator and the cumulative baseline hazard as described [36, 37].

Results from the Cox regression models using complete cases and MICE were similar. The imputed data set had different HR's by around \pm 0.05 in the majority of estimates for any mental health, internalising, other, and developmental delay, with more variation in maternal smoking \pm 0.15 ; for the externalising outcome, the estimates were similar \pm 0.15 , but the youngest maternal age category differed by 0.22 , and 0.45 for maternal smoking. We have therefore presented only results from the multiple imputation analyses. To protect participant confidentiality, counts that were less than five are noted as " $<5$ " and a masked total is given " $\sim$ "; some counts were converted to percentages to retain information and remove disclosure risk if cells were less than five, or disclosure could occur via the use of information across multiple tables.

Univariable analyses were conducted initially to estimate unadjusted (marginal) associations between each ACE and outcomes. Following this, the models were developed in three stages for each of the five mental health diagnoses categories. First, we estimated the hazard ratios (HR) for each mental health diagnosis associated with social deprivation, sociodemographic and perinatal factors. Second, we added the ACE variables and compared the conditional HRs (cHR) from this model to the first model. Third, we fitted a model with two-way product terms between social deprivation (i.e. small-area deprivation) and each ACE in models adjusted for sociodemographic and perinatal factors. Product terms were included one at a time to explore whether small-area deprivation was a moderator of ACEs and child mental health diagnoses. We did this for the outcomes of any mental health (excluding developmental delay), and developmental delay only, as the number of observations for the other outcomes were too small.

The conditional associations between a given ACE and mental health outcome can only be given a causal interpretation if the demographic and perinatal covariates included in the model, along with the other four ACEs, are sufficient to control for all confounding between the ACE in question and the outcome. To quantify the extent to which unmeasured confounding could explain away any such estimated causal effect, $E$ values were calculated for each ACE-outcome relationship [38]. The E value can be interpreted as the minimum strength of association on the risk ratio scale that an unmeasured confounder must have with both the exposure and the outcome, after taking into account the covariates already measured, to explain away the estimated causal effect based on the observed (conditional) exposure-outcome association. Thus, an E value of 1 indicates no "evidence for causality," whereas higher E values represent stronger evidence. We calculate the $\mathrm{E}$ value based on both the estimated conditional HR and the lower limit of its 95\% confidence interval.

\section{Results}

In total 191,035 eligible children born in Wales between 1998 and 2012, listed in the Wales Electronic Cohort for Children were included. The maximum length of followup was just under 15 years. Depending on year of birth, 191,035 children had at least 1 year of follow-up, 181, 874 had up to 5 years of follow-up, 103,089 had up to 8 years follow-up, 61,379 had up to 12 years follow-up and 20,597 were followed up to 15 years.

\section{Cohort statistics}

Sample characteristics were consistent with national population statistics for sociodemographic, ACE and mental diagnosis variables (see Additional file 14, Table 12). In our cohort, 1073 (0.6\%) infants (aged <1 year) had experienced childhood victimisation, as coded during hospital admission and 1617 (1.6\%) children experienced the death of a household member by the time they were aged 4 years. For mental health, 31.3\% $(n=$ $56,839)$ and $0.7 \%(n=1281)$ infants (aged $<1$ year) lived in a household in which an adult had a common mental 
disorder or a serious mental illness, respectively. In addition, $8.4 \%$ lived in a household with an adult who problematically used alcohol. All ACE occurrence percentages increased with longer duration of follow-up, aside from child victimisation.

The prevalence of any mental health diagnoses (excluding developmental delay) ranged from $0.4 \%(n=$ 756) for children aged 1 year to $4 \%(n=826)$ for children aged 12-14 years. Externalising diagnoses were present in $0.8 \%(n=161)$ of children aged $12-14$ years, and internalising diagnoses were present in $2.8 \%(n=$ 584) of children aged $12-14$ years. Furthermore, $0.2 \%$ (n $=370$ ) children had been diagnosed with developmental disorder before their first birthday, and this increased to $4.2 \%(n=866)$ of children aged $12-14$ years.

\section{Cox regression models}

Conditional on all other variables in Model 1 (excluding ACEs), the risk of any mental health diagnosis (excluding developmental delay) was increased among children who lived in the most deprived quintile of social deprivation (estimated cHR 1.32, CI 95\% 1.16-1.51, relative to the least deprived quintile) and who had younger mothers (cHR 1.27, CI 95\% 1.15-1.39). However, female children were at a reduced risk (cHR 0.79, CI 95\% 0.730.84) as were non first-born children (cHR 0.90, CI 95\% 0.84-0.98); see Table 1 for more details.

The inclusion of the ACE variables slightly reduced the estimated cHRs above, but an estimated conditional association between social deprivation and child mental health diagnosis remained. Living with a household member who had a common mental disorder was conditionally associated with an increased risk of any mental health diagnosis (cHR 1.63, CI 95\% 1.52-1.75). Likewise, experiencing victimisation was conditionally associated with an almost doubled risk of any mental health diagnosis (cHR 1.90, CI 95\% 1.34-2.69). There was relatively weaker evidence $(p>0.05)$ for a conditional association between the other ACEs (living with an adult who had alcohol problems or serious mental illness, death of a household member) and having a mental health diagnosis or symptoms in childhood. The E value for common mental health disorder was 2.15 , meaning that unmeasured confounding could fully explain the estimated conditional association if there were an unmeasured confounder having a relative risk association at least as large as 2.15 with both common mental health disorder of a household member and any mental health diagnosis in the child. The corresponding $\mathrm{E}$ value for the lower $95 \%$ confidence limit $(\mathrm{CL})$ is 2.01 , meaning that unmeasured confounding would overturn the statistical significance of the estimated effect if an unmeasured confounder had relative risk associations of at least 2.01 with both exposure and outcome. The corresponding $\mathrm{E}$ values for victimisation was 3.21 (2.01 lower 95\% CL), should be considered in the context of the estimated conditional HRs for all of the ACEs and confounders (see the right most column of Table 1), which are all less than 2. With the exception of victimisation, each of the upper 95\% CLs is also less than 2. This suggests that it is somewhat implausible that unmeasured confounding fully explains the estimated effects above.

For externalising diagnoses, living with an adult who had a common mental health disorder was conditionally associated with an almost two and a half times increased risk of diagnosis (cHR 2.37, CI 95\% 1.99-2.82). The presence of victimisation was conditionally associated with an increased risk of almost three and a half times (cHR 3.45, CI 95\% 2.09-5.69); see Table 2 and Additional file 4, Table 2 for the full model and sociodemographic and perinatal only model (Model 1 ). The E value for common mental health disorder was 3.02 (2.59 for the lower 95\% CL), and victimisation was 6.36 (3.60 for the lower 95\% CL). Although these are higher than the $\mathrm{E}$ values for the previous outcome (any mental health diagnosis), the strength of evidence for causality needs partly to be calibrated against the higher estimated cHRs for the exposures and measured confounders for the externalising diagnoses outcome.

These patterns were similarly reflected in the analyses with internalising symptoms as the outcome, with the common mental health disorder ACE estimated to be conditionally associated with a less pronounced but still increased risk (cHR 1.52 CI 95\% 1.39-1.65); the evidence for conditional associations with the other ACEs was weaker $(p>0.05)$, see Table 3 and Additional file 5, Table 3 for the full model and sociodemographic and perinatal only model (Model 1 ). The $\mathrm{E}$ value for common mental health disorder in this analysis was 2.01 (1.82 for the lower 95\% CL). Again, these should partly be interpreted in relation to the estimated cHR for this outcome, which are all lower, suggesting again that it is perhaps unlikely that unmeasured confounding could explain away the estimated effect entirely.

For other mental health diagnoses, alcohol admission or problem in the household was conditionally associated with increased risk (cHR 1.33 CI 95\% 1.02-1.73), as was common mental health disorder (cHR 1.58 CI 95\% $1.32-1.90)$. There was only relatively weaker evidence $(p>0.05)$ for the conditional association of the other ACEs with the outcome, see Table 4 for ACEs, and Additional file 6 , Table 4 for the full model and sociodemographic and perinatal only model (Model 1). Alcohol admission/problem had an E value of 1.73 (1.13 for the lower $\mathrm{CL}$ ) and common mental health disorder had an $\mathrm{E}$ value of 2.09 (1.72 for the lower $\mathrm{CL}$ ). These $\mathrm{E}$ values are closer in magnitude to the estimated cHRs, and thus, the evidence for causality is weaker here. 
Table 1 Prevalence and results from Cox regressions of any mental health outcomes (excluding developmental delay). Univariable, sociodemographic and perinatal only (Model 1) and including ACEs (Model 2)

Any mental health diagnoses or symptoms (excluding developmental delay) (HR 95\% Cl)

\begin{tabular}{llll}
$\begin{array}{l}\text { Prevalence for those } \\
\text { diagnosed }(n=3571)\end{array}$ & Univariable & $\begin{array}{l}\text { Social deprivation, demographic } \\
\text { and perinatal variables }\end{array}$ & $\begin{array}{l}\text { ACEs adjusted for demographic } \\
\text { and perinatal variables }\end{array}$ \\
\hline
\end{tabular}

\section{Ever any household member with an alcohol-related hospital admission}

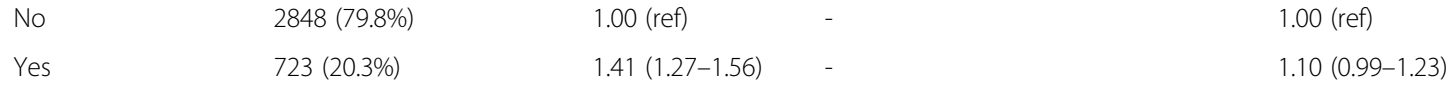

Ever death of any household member

\begin{tabular}{|c|c|c|c|c|}
\hline No & 3571 (100\%) & 1.00 (ref) & 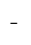 & 1.00 (ref) \\
\hline Yes & $<5$ & $1.01(0.73-1.39)$ & - & $0.92(0.67-1.27)$ \\
\hline
\end{tabular}

Household member ever had a common mental health disorder or psychosis GP code

\begin{tabular}{|c|c|c|c|c|}
\hline No & $1232(34.5 \%)$ & 1.00 (ref) & - & 1.00 (ref) \\
\hline Yes & $2339(65.5 \%)$ & $1.74(1.63-1.87)$ & - & $1.63(1.52-1.75)$ \\
\hline
\end{tabular}

Household member ever had a serious mental illness GP code

\begin{tabular}{|c|c|c|c|c|}
\hline No & 3478 (97.4\%) & 1.00 (ref) & - & 1.00 (ref) \\
\hline Yes & $93(2.6 \%)$ & $1.77(1.30-2.41)$ & - & 1.35 (0.99-1.84) \\
\hline
\end{tabular}

Any childhood victimisation hospital admission

$\begin{array}{lllll}\text { No } & 3471(97.2 \%) & 1.00(\text { ref } & - & 1.00 \text { (ref) } \\ \text { Yes } & 100(2.8 \%) & 2.40(1.69-3.40) & - & 1.90(1.34-2.69)\end{array}$

Ever in a single parent household

$\begin{array}{lllll}\text { No } & 2054(57.5 \%) & 1.00(\text { ref }) & 1.00 \text { (ref) } & 1.00 \text { (ref) } \\ \text { Yes } & 1517(42.5 \%) & 1.13(1.04-1.22) & 1.00(0.92-1.08) & 1.03(0.95-1.11)\end{array}$

Townsend deprivation quintile at birth or in first 4 months $(0.4 \%$ missing data)

$\begin{array}{lllll}1 \text { (least deprived) } & 494(13.8 \%) & 1.00 \text { (ref) } & 1.00 \text { (ref) } & 1.00 \text { (ref) } \\ 2 & 590(16.5 \%) & 1.18(1.04-1.34) & 1.13(0.99-1.28) & 1.12(0.99-1.27) \\ 3 & 675(18.9 \%) & 1.29(1.15-1.46) & 1.17(1.03-1.32) & 1.14(1.01-1.29) \\ 4 & 772(21.6 \%) & 1.42(1.26-1.60) & 1.23(1.09-1.40) & 1.19(1.05-1.35) \\ 5 \text { (most deprived) } & 1027(28.8 \%) & 1.63(1.46-1.83) & 1.32(1.16-1.51) & 1.26(1.11-1.43) \\ \text { Sex } & & & & 1.00 \text { (ref) } \\ \text { Male } & 2059(57.7 \%) & 1.00(\text { ref) } & 1.00(\text { ref }) & 0.79(0.74-0.85)\end{array}$

Breastfeeding at birth or 6-8 weeks (20.8\% missing data)

\begin{tabular}{|c|c|c|c|c|}
\hline No & $1490(41.7 \%)$ & 1.00 (ref) & 1.00 (ref) & 1.00 (ref) \\
\hline Yes & $1338(37.5 \%)$ & $0.78(0.72-0.85)$ & $0.88(0.81-0.96)$ & $0.90(0.82-0.98)$ \\
\hline
\end{tabular}

Maternal age at birth or at 6-8 weeks ( $<5$ missing)

$\begin{array}{lllll}30-34 \text { years } & 12 \% & 0.84(0.76-0.92) & 0.89(0.80-0.98) & 0.91(0.82-1.01) \\ \geq 35 \text { years } & 23 \% & 0.80(0.72-0.91) & 0.87(0.77-0.99) & 0.89(0.78-1.00) \\ 25-29 \text { years } & 28 \% & 1.00(\text { ref }) & 1.00 \text { (ref) } & 1.00 \text { (ref) } \\ <18 \text { years } & 3 \% & 1.37(1.12-1.69) & 1.14(0.92-1.42) & 1.09(0.88-1.36) \\ 18-24 \text { years } & 34 \% & 1.40(1.28-1.53) & 1.27(1.15-1.39) & 1.22(1.11-1.35) \\ \text { Gestational age at birth }(\mathbf{4 . 2} \% \text { missing data) } & & & 1.03(0.53-1.99) \\ 24 \leq 28 \text { weeks } & 11(0.3 \%) & 1.15(0.60-2.22) & 1.07(0.55-2.07) & 1.05(0.74-1.43) \\ 28 \leq 33 \text { weeks } & 47(1.3 \%) & 1.13(0.84-1.52) & 1.09(0.81-1.48) & 1.22(1.05-1.42) \\ 33 \leq 37 \text { weeks } & 246(6.9 \%) & 1.24(1.08-1.43) & 1.24(1.06-1.44) & 1.00(\text { ref })\end{array}$


Table 1 Prevalence and results from Cox regressions of any mental health outcomes (excluding developmental delay). Univariable, sociodemographic and perinatal only (Model 1) and including ACEs (Model 2) (Continued)

\begin{tabular}{|c|c|c|c|c|}
\hline \multicolumn{5}{|c|}{ Any mental health diagnoses or symptoms (excluding developmental delay) (HR 95\% Cl) } \\
\hline & $\begin{array}{l}\text { Prevalence for those } \\
\text { diagnosed }(n=3571)\end{array}$ & Univariable & $\begin{array}{l}\text { Social deprivation, demographic } \\
\text { and perinatal variables }\end{array}$ & $\begin{array}{l}\text { ACEs adjusted for demographic } \\
\text { and perinatal variables }\end{array}$ \\
\hline \multicolumn{5}{|c|}{ Parity (0.2\% missing data) } \\
\hline 0 & $1671(46.8 \%)$ & 1.00 (ref) & 1.00 (ref) & 1.00 (ref) \\
\hline$\geq 1$ & $1892(53.0 \%)$ & $0.84(0.79-0.91)$ & $0.90(0.84-0.98)$ & $0.88(0.82-0.95)$ \\
\hline \multicolumn{5}{|c|}{ Multiple births } \\
\hline No & 3480 (97.5\%) & 1.00 (ref) & 1.00 (ref) & 1.00 (ref) \\
\hline Yes & $91(2.5 \%)$ & $0.83(0.66-1.03)$ & $0.79(0.63-1.00)$ & $0.80(0.64-1.01)$ \\
\hline \multicolumn{5}{|c|}{ Small for gestational age ( $<10$ th centile) $(4.9 \%$ missing data) } \\
\hline No & $3027(84.8 \%)$ & 1.00 (ref) & 1.00 (ref) & 1.00 (ref) \\
\hline Yes & $369(10.3 \%)$ & $1.21(1.08-1.36)$ & $1.11(0.99-1.25)$ & $1.10(0.97-1.24)$ \\
\hline \multicolumn{5}{|c|}{ Congenital anomalies } \\
\hline None & 3341 (93.6\%) & 1.00 (ref) & 1.00 (ref) & 1.00 (ref) \\
\hline Minor & $27(0.8 \%)$ & $1.02(0.68-1.53)$ & $0.96(0.64-1.45)$ & $0.95(0.63-1.44)$ \\
\hline Major & $203(5.7 \%)$ & $1.55(1.34-1.80)$ & $1.51(1.30-1.75)$ & $1.50(1.29-1.74)$ \\
\hline \multicolumn{5}{|c|}{ Maternal cigarette smoking at booking in $(71.3 \%$ missing data) } \\
\hline No & $739(20.7 \%)$ & 1.00 (ref) & 1.00 (ref) & 1.00 (ref) \\
\hline Yes & 285 (8.0\%) & $1.41(1.08-1.84)$ & $1.20(0.89-1.63)$ & $1.19(0.88-1.60)$ \\
\hline
\end{tabular}

Table 2 Prevalence and results from Cox regressions of Externalising diagnosis or symptoms. Univariable and adjusted ACEs model (Model 2); see Additional file 4, Table 2 for sociodemographic and perinatal only (Model 1)

\begin{tabular}{ccc}
\hline Externalising mental health diagnoses or symptoms (HR 95\% Cl) \\
\hline $\begin{array}{l}\text { Prevalence for } \\
\text { those diagnosed }\end{array}$ & Univariable & $\begin{array}{l}\text { ACEs adjusted for } \\
\text { demographic and } \\
(n=667)\end{array}$ \\
perinatal variables
\end{tabular}

Ever any household member with an alcohol-related hospital admission

$$
\begin{array}{llll}
\text { No } & 499(74.8 \%) & 1.00 \text { (ref) } & 1.00 \text { (ref) } \\
\text { Yes } & 168(25.2 \%) & 1.81(1.45-2.27) & 1.14(0.90-1.43)
\end{array}
$$

Ever death of any household member

$$
\begin{array}{llll}
\text { No } & \sim 667(100 \%) & 1.00 \text { (ref) } & 1.00 \text { (ref) } \\
\text { Yes } & <5 & 0.57(0.24-1.38) & 0.48(0.20-1.16)
\end{array}
$$

Household member ever had a common mental health disorder or psychosis READ code

$$
\begin{array}{llll}
\text { No } & 184(27.6 \%) & 1.00 \text { (ref) } & 1.00 \text { (ref) } \\
\text { Yes } & 483(72.4 \%) & 2.75(2.32-3.27) & 2.37(1.99-2.82)
\end{array}
$$

Household member ever had a serious mental illness READ code

$$
\begin{array}{llll}
\text { No } & 645(96.7 \%) & 1.00 \text { (ref) } & 1.00 \text { (ref) } \\
\text { Yes } & 22(3.3 \%) & 2.58(1.42-4.68) & 1.68(0.92-3.07)
\end{array}
$$

Any childhood victimisation hospital admission

$\begin{array}{llll}\text { No } & 638(95.7 \%) & 1.00 \text { (ref) } & 1.00 \text { (ref) } \\ \text { Yes } & 29(4.4 \%) & 5.27(3.21-8.67) & 3.45(2.09-5.69)\end{array}$

Table 3 Prevalence and results from Cox regressions of Internalising diagnosis or symptoms. Univariable and adjusted ACEs model (Model 2); see Additional file 5, Table 3 for sociodemographic and perinatal only (Model 1)

\begin{tabular}{ccc}
\hline Internalising mental health diagnoses or symptoms (HR 95\% Cl) \\
\hline $\begin{array}{l}\text { Prevalence for } \\
\text { those diagnosed } \\
(n=2424)\end{array}$ & Univariable & $\begin{array}{l}\text { ACEs adjusted for } \\
\text { demographic and } \\
\text { perinatal variables }\end{array}$ \\
\hline
\end{tabular}

Ever any household member with an alcohol-related hospital admission

$$
\begin{array}{llll}
\text { No } & 1969(81.2 \%) & 1.00 \text { (ref) } & 1.00 \text { (ref) } \\
\text { Yes } & 455(18.8 \%) & 1.24(1.09-1.42) & 1.04(0.91-1.20)
\end{array}
$$

Ever death of any household member

$$
\begin{array}{llll}
\text { No } & \sim 2424(100 \%) & 1.00 \text { (ref) } & 1.00 \text { (ref) } \\
\text { Yes } & <5 & 1.14(0.79-1.64) & 1.08(0.75-1.56)
\end{array}
$$

Household member ever had a common mental health disorder or psychosis READ code

$$
\begin{array}{llll}
\text { No } & 869(35.9 \%) & 1.00 \text { (ref) } & 1.00 \text { (ref) } \\
\text { Yes } & 1555(64.2 \%) & 1.56(1.44-1.70) & 1.52(1.39-1.65)
\end{array}
$$

Household member ever had a serious mental illness READ code

$$
\begin{array}{llll}
\text { No } & 2376(98.0 \%) & 1.00 \text { (ref) } & 1.00 \text { (ref) } \\
\text { Yes } & 48(2.0 \%) & 0.99(0.61-1.62) & 0.80(0.49-1.31)
\end{array}
$$

Any childhood victimisation hospital admission

\begin{tabular}{llll} 
No & $2386(98.4 \%)$ & 1.00 (ref) & 1.00 (ref) \\
Yes & $38(1.6 \%)$ & $1.26(0.70-2.29)$ & $1.08(0.60-1.95)$ \\
\hline
\end{tabular}


Table 4 Prevalence and results from Cox regressions of Other diagnosis or symptoms. Univariable and adjusted ACEs model (Model 2); see Additional file 6, Table 4 for sociodemographic and perinatal only (Model 1)

\begin{tabular}{|c|c|c|}
\hline \multicolumn{3}{|c|}{ Other mental health diagnoses or symptoms (HR 95\% Cl) } \\
\hline $\begin{array}{l}\text { Prevalence for } \\
\text { those diagnosed } \\
\text { ( } n=547)\end{array}$ & Univariable & $\begin{array}{l}\text { ACEs adjusted for } \\
\text { demographic and } \\
\text { perinatal variables }\end{array}$ \\
\hline
\end{tabular}

Ever any household member with an alcohol-related hospital admission

$$
\begin{array}{llll}
\text { No } & 432(79.0 \%) & 1.00(\text { ref }) & 1.00 \text { (ref) } \\
\text { Yes } & 115(21.0 \%) & 1.70(1.32-2.20) & 1.33(1.02-1.73)
\end{array}
$$

Ever death of any household member

$\begin{array}{llll}\text { No } & \sim 547(100 \%) & 1.00 \text { (ref) } & 1.00 \text { (ref) } \\ \text { Yes } & <5 & 0.45(0.11-1.83) & 0.40(0.10-1.64)\end{array}$

Household member ever had a common mental health disorder or psychosis GP code

$\begin{array}{llll}\text { No } & 193(35.3 \%) & 1.00(\text { ref }) & 1.00 \text { (ref) } \\ \text { Yes } & 354(64.7 \%) & 1.78(1.49-2.13) & 1.58(1.32-1.90)\end{array}$

Household member ever had a serious mental illness GP code

$\begin{array}{llll}\text { No } & 529(96.7 \%) & 1.00 \text { (ref) } & 1.00 \text { (ref) } \\ \text { Yes } & 18(3.3 \%) & 2.61(1.35-5.04) & 1.87(0.96-3.64)\end{array}$

Any childhood victimisation hospital admission

$\begin{array}{llll}\text { No } & 522(95.4 \%) & 1.00(\text { ref }) & 1.00 \text { (ref) } \\ \text { Yes } & 25(4.6 \%) & 2.52(1.13-5.64) & 1.86(0.83-4.17)\end{array}$

Exposure to ACEs was also conditionally associated with an increased risk of developmental delay. Alcohol problem (cHR 1.12 CI 95\% 1.02-1.23), common mental health disorder (cHR 1.42 CI 95\% 1.33-1.51) and victimisation (cHR 1.65 CI 95\% 1.23-2.20) were all conditionally associated with an increased risk; see Table 5 for ACEs, and Additional file 7, Table 5 for the full model and sociodemographic and perinatal only model (Model 1). Common mental health disorder had an $E$ value of 1.87 (lower CL 1.73), alcohol admission/problem was 1.49 (lower CL 1.16), and victimisation was 2.69 (lower CL 1.76). As with the previous analysis, and especially for the alcohol exposure, the evidence for causality is therefore rather weak.

To better understand the combined effects of ACEs and deprivation, three-way cross tabulations of ACEs and deprivation across the two categories of any mental health (excluding developmental delay), and developmental delay were explored. This showed that the most deprived category experienced a higher proportion of ACEs compared to the least deprived; see Additional files 8 and 9, Tables 6 and 7. We explored whether deprivation moderated the relationship between ACEs and child mental health. However, there was very little evidence of larger effect sizes for the five levels of deprivation, or a gradient, as only a single association
Table 5 Prevalence and Cox regressions of Developmental Delay diagnosis. Univariable and adjusted ACE's model (Model 2); see Additional file 7, Table 5 for sociodemographic and perinatal only (Model 1)

Developmental delay (HR 95\% Cl)

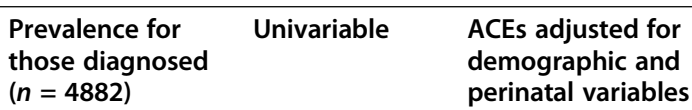

Ever any household member with an alcohol-related hospital admission

$\begin{array}{llll}\text { No } & 3891(79.7 \%) & 1.00 \text { (ref) } & 1.00 \text { (ref) } \\ \text { Yes } & 991(20.3 \%) & 1.36(1.24-1.49) & 1.12(1.02-1.23)\end{array}$

Ever death of any household member

$\begin{array}{llll}\text { No } & 4870(99.8 \%) & 1.00(\mathrm{ref}) & 1.00 \text { (ref) } \\ \text { Yes } & 12(0.3 \%) & 1.12(0.81-1.54) & 1.03(0.75-1.42)\end{array}$

Household member ever had a common mental health disorder or psychosis READ code

$$
\begin{array}{llll}
\text { No } & 1836(37.6 \%) & 1.00(\text { ref }) & 1.00 \text { (ref) } \\
\text { Yes } & 3046(62.4 \%) & 1.52(1.43-1.61) & 1.42(1.33-1.51)
\end{array}
$$

Household member ever had a serious mental illness READ code

$\begin{array}{llll}\text { No } & 4786(98.0 \%) & 1.00 \text { (ref) } & 1.00 \text { (ref) } \\ \text { Yes } & 96(2.0 \%) & 1.26(0.92-1.72) & 0.99(0.72-1.35)\end{array}$

Any childhood victimisation hospital admission

\begin{tabular}{llll} 
No & $4736(97.0 \%)$ & 1.00 (ref) & 1.00 (ref) \\
Yes & $146(3.0 \%)$ & $2.17(1.63-2.89)$ & $1.65(1.23-2.20)$ \\
\hline
\end{tabular}

was statistically significant between common mental health disorder and the most deprived group for developmental delay ( $\mathrm{cHR} 0.81, p<0.05$ ), this should not be emphasised given the issue of multiple testing; see Additional file 15, Table 13 for models. Therefore, we found insufficient evidence to conclude that the conditional association between these five ACEs and child mental health outcomes were moderated by deprivation.

\section{Discussion}

This study has explored the effects of five individual ACEs on child mental health, going beyond cumulative measures which can obscure the relative contribution of individual adversity [10, 11, 39]. After adjusting for a number of demographic and perinatal factors, we found that living with an adult who had a common mental disorder was consistently associated with an increased risk of internalising symptoms, externalising symptoms, and developmental delay. Likewise, experiencing victimisation was conditionally associated with an increased risk of any mental health diagnosis (excluding developmental delay), developmental delay and externalising symptoms, where there was an estimated three-fold increase in the conditional rate of diagnosis. Living with an adult with alcohol-related problems or admission was a significant predictor of other mental health diagnoses and 
developmental delay; however, these cHRs were smaller compared to other ACEs. Serious mental illness and death of a household member had no statistically significant associations with child mental health; this may be due to the rarity of these exposures.

While the relationship between ACEs and child mental health is complex, our study aligns and builds on wider research, notably studies which examined the association between one or two ACEs and child mental health $[10,11]$. First, we found that common mental health disorders among household members were consistently conditionally associated with all child mental health outcomes. Research on individual ACEs by Merrick et al. found that household mental illness increased depressed affect and suicide attempt. Alongside this, our findings align with a review which found that parental mood disorders increase the risk for child internalising symptoms, externalising symptoms, medical difficulties and developmental delay $[40,41]$. Hence, we argue that living with an adult with a common mental health disorder can be a considerable risk factor for an array of child mental health outcomes.

Second, we found associations between alcohol problems or admissions for other mental health diagnoses (e.g. eating disorders, personality disorders) and developmental delay. In our study, it was unprecedented that there was no evidence of alcohol admissions or problems being associated with externalising symptoms. Our findings support Hussong et al. who did not find an association with internalising symptoms [15], but do not support the association with externalising symptoms [14]. Moreover, they do not support Finan et al. (2015) who found maternal alcohol use was associated with aggressive behaviour and externalising symptoms; they note that there were different mediation pathways for boys and girls through family functioning [42]. We suspect that the null result observed could be due to gender differences, the low likelihood of being diagnosed at that age, or that our measure of alcohol problems were not sufficiently sensitive to capture this.

Nevertheless, our findings can be explained by several theories, but most notably parenting, the family environment and theories of intra-generational transmission. Parenting and the family environment can be altered in situations where the parent is experiencing mental health problems or substance dependence or problems [43-45]. For instance, Davis et al. found that parents who experience depression were more likely to use punitive discipline and implement fewer household routines [46], and Smith states that these behaviours can negatively impact child wellbeing broadly, but specifically child mental health [47]. Parental mental health and substance use may also increase household conflict [43, 48, 49], which is also associated with child mental health [50].
Victimisation was also consistently associated with child mental health in this study. While only a small proportion of children in our sample was recorded as having a childhood victimisation hospital admission, our findings support that abuse is coded only in a small number of cases in hospital settings (1\%) [51]. Our findings align with other research that identifies that victimisation has a profound impact on child mental health [52-54]. For instance, Nelson et al. conducted a systematic review and found that children who experienced non-sexual child maltreatment had increased mental health disorders and suicide attempts. Therefore, we further highlight the profound effect victimisation can have on child mental health diagnoses, specifically developmental delay and externalising symptoms.

Alongside ACEs, socio-demographic and perinatal aspects were also associated with the rate of diagnosis. Most notably, deprivation was consistently associated with higher rates of child mental health outcomes, which echoes Reiss [18]. Females were less likely to have a diagnosis compared to males across every outcome. This was unexpected as often females are more likely to exhibit greater mental health disorders [55]; however, we attribute this to age-related differences. Younger mothers had children with a steeper rate of diagnosis, and maternal smoking was associated with any mental health (excluding developmental delay), externalising symptoms and developmental delay; this is further evidenced in other studies, particularly for externalising symptoms [56, 57].

Alongside evaluating individual associations, our analysis explored whether deprivation could moderate the relationship between ACEs and child mental health outcomes. We found that although ACEs are socially patterned, the effects of social deprivation on child mental health are not fully explained through the five ACEs used in this analysis. We found evidence that both social deprivation and ACEs independently increase the risk of mental health diagnoses in children, with no strong evidence to reject additivity of these effects on the conditional log hazard ratio scale. However, other studies, such as Font and Maguire-Jack [58], found that socioeconomic status was a key mediator in the relationship between ACEs and adult depression. Straatmann et al. suggest ACEs mediate the association between socioeconomic status and adolescent health outcomes so there is a complex interrelationship between ACEs, socioeconomic status, and child mental health which was not fully addressed by our study [59].

Nevertheless, our research has a number of strengths. First, we do not rely on self-reported data (e.g. Felitti et al. 1998) which may be subject to poor recall [60] as the accuracy of retrospective reports of childhood events can be influenced by any number of factors, including 
the child's age, memory difficulties, wanting to protect parents, a desire to deny or forget the past, or methodological research issues [61]. Second, our study adopted a unique approach compared with existing work in this area using a large number of unselected participants from a total population cohort and longitudinal followup over 14 years. This data permitted statistical analysis that controlled for many potentially confounding factors related to child mental health and that respected the temporal relationship between exposures and outcomes.

However, previous research has highlighted that GPs report difficulties in the recognition and detection of mental health signs and symptoms in young people compared to adult mental health, where GPs have at their disposal a checklist that helps decide on the need for a referral [62]. With regard to ACE variables, the use of ICD-10 codes to classify child victimisation has been previously found to be underestimated [63]. This is due to doctors not recognising and documenting abuse and clinical coders not being diligent in their coding; however, externalising symptoms are easier to recognise, as documented by the increased prevalence in this study [64]. Several adverse childhood events could not be measured with routine data, such as domestic violence, incarceration, and sexual and physical abuse, and parental drug use [65].

Moreover, we do not assess multiple events, cumulative scoring or chronic exposure in our study, and we encourage future research to compare these where possible. There would have been participants who required treatment for childhood mental health disorders, but for whom there was a sufficient lag between needing treatment and being diagnosed or treated who would have been unidentified in our study. While we included many potential confounders in our analyses, it is likely that the conditional associations we report still cannot be given a causal interpretation due to unmeasured confounding, for example by ethnicity. Yet further caution is required given that conditional hazard ratios present particular difficulties for causal interpretability [66]. However, as demonstrated by the calculated $E$ values, the strength of unmeasured confounding would need to be considerable (arguably implausibly so) for most of our estimated effects to be explained away entirely.

From this, we suggest that future work should explore the association between ACEs and child mental health further, including examining factors that may mediate the relationship, such as maladaptive coping strategies for dealing with stress, and those that may moderate the relationship such as the role of protective factors. Moreover, considerable work is required to understand how socioeconomic status dynamically operates alongside ACEs, and the public health implications this has [19, 20]. Likewise, the relationship between positive childhood experiences and child mental health should be explored, given that evidence suggests that mental health is more than just the absence of adversity [67]. Furthermore, while this study investigated the impact of household mental health diagnoses on child mental health, there may be reciprocity, which should be further explored.

\section{Conclusions}

Our findings evidence the importance of the caregiving environment and social conditions for child mental health. They show conditional associations between sociodemographic factors, perinatal aspects, and ACEs specifically common mental health disorders and victimisation, with child mental health outcomes. However, we did not find evidence for moderation of the effect of ACEs by deprivation. Our findings offer further evidence to support the need for structural interventions, reducing modifiable socioeconomic inequalities, and the early identification and evidence-based intervention for all children who have experienced ACEs [68, 69]; models such as the Building Community Resilience (BCR) have been viewed as positive [69]; however, interventions using $\mathrm{ACE}$ screening require further research to establish their effectiveness [70].

\section{Abbreviations}

ACEs: Adverse childhood experiences; cHR: Conditional HRs; Cl: Confidence interval; CL: Confidence limit; DAG: Directed acyclic graph; GP: General practice; HR: Hazard ratios; MICE: Multiple imputation with chained equations; NHS: National Health Service; NWIS: NHS Wales Informatics Service; RALFs: Residential Anonymised Linking Field; SAIL: Secure Anonymised Information Linkage; SDQ: Strengths and Difficulties Questionnaire; WECC: Wales Electronic Cohort for Children

\section{Supplementary Information}

The online version contains supplementary material available at https://doi. org/10.1186/s12916-021-02045-x

Additional file 1: Figure 1. Participant Selection.

Additional file 2: Figure 2. Directed acyclic graph of exposure to ACEs and child mental health outcome at 8 years.

Additional file 3: Table 1. Sociodemographic and perinatal characteristics in each exposure.

Additional file 4: Table 2. Externalising Symptoms (Table 2 continued for confounders) prevalence, univariable analyses, sociodemographic and perinatal aspects, and ACEs Cox regression.

Additional file 5: Table 3. Internalising Symptoms (Table 3 continued for confounders) prevalence, univariable analyses, sociodemographic and perinatal aspects, and ACEs Cox regression.

Additional file 6: Table 4. Other diagnosis or symptom (Table 4 continued for confounders) prevalence, univariable analyses, sociodemographic and perinatal aspects, and ACEs Cox regression. Additional file 7: Table 5. Developmental delay (Table 5 continued for confounders) prevalence, univariable analyses, sociodemographic and perinatal aspects, and ACEs Cox regression.

Additional file 8: Table 6. Three-way cross-tabulation of ACEs, Deprivation and Any Mental Health (excluding developmental delay). 
Additional file 9: Table 7. Three-way cross-tabulation of ACEs, Deprivation and Developmental Delay.

Additional file 10: Table 8. Adult Mental Health codes for Common Mental Disorder (CMD) and Serious Mental Illness (SMI).

Additional file 11: Table 9. Codes for Externalising and Internalising categories

Additional file 12: Table 10. Codes for Other and Developmental delay.

Additional file 13: Table 11. ICD-10 codes for victimisation, taken from Lee, Gonzalez-Izquierod, and Gilbert (2012) [27]

Additional file 14: Table 12. Table of national population statistics. Additional file 15: Table 13. Moderation analysis for ACEs, deprivation, and child mental health.

\section{Acknowledgements}

We thank the SAIL databank for assisting in the statistical disclosure process.

\section{Authors' contributions}

$S P, S L$ and $M A B$ had the original idea for this study. SP, AE, RA, EL and RD designed the study and developed the analysis plan. AJ provided advice on the mental health codes used in this analysis. AB extracted the data and prepared data sets for analysis. EM, AE and RA analysed the data. EM and RA wrote the first draft of the paper. The authors were involved in interpreting the findings, revising drafts, and agreeing the final version.

\section{Funding}

Data is collected routinely and access to this was granted via the SAIL databank. The corresponding author had full access to all the data in the study and final responsibility for the decision to submit for publication. The data sets generated and analysed during the current study are available in the SAIL databank repository, https://saildatabank.com/. This work was supported by funds from the Economic and Social Research Council, the Medical Research Council and Alcohol Research UK to the ELAStiC Project (ESL015471/1) and Public Health Wales. The views expressed are those of the authors and should not be assumed to be of the funding body. The research was also supported by The Centre for the Development and Evaluation of Complex Interventions for Public Health Improvement, a UK Clinical Research Collaboration Public Health Research Centre of Excellence. This work was supported by the Health Data Research UK, which receives its funding from HDR UK Ltd. (HDR-9006) funded by the UK Medical Research Council, Engineering and Physical Sciences Research Council, Economic and Social Research Council, Department of Health and Social Care (England), Chief Scientist Office of the Scottish Government Health and Social Care Directorates, Health and Social Care Research and Development Division (Welsh Government), Public Health Agency (Northern Ireland), British Heart Foundation (BHF) and the Wellcome Trust. The funders had no role in designing the study, data collection, analysis, or interpretation, or in writing the report; $M A B^{\prime}$ s role in the design, analysis and writing was independent of the funding from Public Health Wales.

\section{Declarations}

Ethics approval and consent to participate

Data is routinely collected, and access and use were approved by the SAIL Databank.

\section{Competing interests}

The authors declare that they have no competing interests.

\section{Author details}

${ }^{1}$ Population Data Science, Swansea University Medical School, Singleton Park, Swansea SA2 8PP, UK. '2DECIPHer, 1 - 3 Museum Place, School of Social Sciences, Cardiff University, Cardiff CF10 3BD, UK. ${ }^{3}$ Wolfson Centre for Young People's Mental Health, Cardiff University, Cardiff, UK. ${ }^{4}$ Division of Population Medicine, Neuadd Meirionnydd, University Hospital of Wales, Heath Park, Cardiff CF14 4YS, UK. ${ }^{5}$ National Centre for Population Health and Wellbeing Research, Swansea University Medical School, Singleton Park, Swansea SA2 8PP, UK. ${ }^{6}$ College of Human Sciences, Bangor University, Wrexham
Technology Park, Bangor LL13 7YP, UK. University of Aberdeen, Aberdeen Health Data Science Centre, Institute of Applied Health Sciences, Polwarth Building, Foresterhill, Aberdeen AB25 2ZD, UK.

Received: 6 April 2021 Accepted: 23 June 2021

Published online: 06 August 2021

\section{References}

1. Felitti VJ, Anda RF, Nordenberg D, Williamson DF, Spitz AM, Edwards V, et al. Relationship of childhood abuse and household dysfunction to many of the leading causes of death in adults. The Adverse Childhood Experiences (ACE) Study. Am J Prev Med. 1998;14(4):245-58. https://doi.org/10.1016/S0749-3 797(98)00017-8.

2. Bellis MA, Hughes $K$, Leckenby $N$, Perkins C, Lowey $H$. National household survey of adverse childhood experiences and their relationship with resilience to health-harming behaviors in England. BMC Med. 2014;12(1):72. https://doi.org/10.1186/1741-7015-12-72.

3. Oh DL, Jerman P, Silvério Marques S, Koita K, Purewal Boparai SK, Burke Harris $\mathrm{N}$, et al. Systematic review of pediatric health outcomes associated with childhood adversity. BMC Pediatr. 2018;18 Available from: https://www. ncbi.nlm.nih.gov/pmc/articles/PMC5824569/. Cited 2021 Mar 18.

4. Hughes K, Bellis MA, Hardcastle KA, Sethi D, Butchart A, Mikton C, et al. The effect of multiple adverse childhood experiences on health: a systematic review and meta-analysis. Lancet Public Health. 2017;2(8):e356-66. https:// doi.org/10.1016/S2468-2667(17)30118-4

5. Asmussen K, McBride T, Waddell S. The potential of early intervention for preventing and reducing ACE-related trauma. Soc Policy Soc. 2019;18(3): 425-34. https://doi.org/10.1017/S1474746419000071.

6. Nelson CA, Bhutta ZA, Harris NB, Danese A, Samara M. Adversity in childhood is linked to mental and physical health throughout life. BMJ. 2020;371(m3048):9.

7. Green H, McGinnity Á, Meltzer H, Ford T, Goodman R. Mental health of children and young people in Great Britain. Hampshire: Palgrave Macmillian 2005. Available from: https://sp.ukdataservice.ac.uk/doc/5269/mrdoc/pdf/52 69technicalreport.pdf

8. Fryers T, Brugha T. Childhood determinants of adult psychiatric disorder. Clin Pract Epidemiol Ment Health. 2013;9(1):1-50. https://doi.org/10.2174/1 745017901309010001

9. Liming KW, Grube WA. Wellbeing outcomes for children exposed to multiple adverse experiences in early childhood: a systematic review. Child Adolesc Soc Work J. 2018;35(4):317-35. https://doi.org/10.1007/s10560-0180532-х.

10. Merrick MT, Ports KA, Ford DC, Afifi TO, Gershoff ET, Grogan-Kaylor A. Unpacking the impact of adverse childhood experiences on adult mental health. Child Abuse Negl. 2017;69:10-9. https://doi.org/10.1016/j.chiabu.201 7.03.016.

11. Negriff S. ACEs are not equal: examining the relative impact of household dysfunction versus childhood maltreatment on mental health in adolescence. Soc Sci Med. 2020;245:112696. https://doi.org/10.1016/j. socscimed.2019.112696.

12. Higgins DJ, McCabe MP. Maltreatment and family dysfunction in childhood and the subsequent adjustment of children and adults. J Fam Violence. 2003;18(2):107-20. https://doi.org/10.1023/A:1022841215113.

13. Ryan KD, Kilmer RP, Cauce AM, Watanabe H, Hoyt DR. Psychological consequences of child maltreatment in homeless adolescents: untangling the unique effects of maltreatment and family environment. Child Abuse Negl. 2000;24(3):333-52. https://doi.org/10.1016/S0145-2134(99)00156-8.

14. Hussong AM, Wirth RJ, Edwards MC, Curran PJ, Chassin LA, Zucker RA. Externalizing symptoms among children of alcoholic parents: entry points for an antisocial pathway to alcoholism. J Abnorm Psychol. 2007;116(3):529_ 42. https://doi.org/10.1037/0021-843X.116.3.529.

15. Hussong AM, Cai L, Curran PJ, Flora DB, Chassin LA, Zucker RA. Disaggregating the Distal, proximal, and time-varying effects of parent alcoholism on children's internalizing symptoms. J Abnorm Child Psychol. 2008;36(3):335-46. https://doi.org/10.1007/s10802-007-9181-9.

16. Ouyang L, Fang X, Mercy J, Perou R, Grosse SD. Attention-deficit/ hyperactivity disorder symptoms and child maltreatment: a populationbased study. J Pediatr. 2008;153(6):851-6. https://doi.org/10.1016/j.jpeds.2 008.06.002.

17. Bøe T, Øverland S, Lundervold AJ, Hysing M. Socioeconomic status and children's mental health: results from the Bergen child study. Soc Psychiatry 
Psychiatr Epidemiol. 2012;47(10):1557-66. https://doi.org/10.1007/s00127011-0462-9.

18. Reiss F. Socioeconomic inequalities and mental health problems in children and adolescents: a systematic review. Soc Sci Med. 2013;90:24-31. https:// doi.org/10.1016/j.socscimed.2013.04.026.

19. Kelly-Irving M, Delpierre C. A critique of the adverse childhood experiences framework in epidemiology and public health: uses and misuses. Soc Policy Soc. 2019;18(3):445-56. https://doi.org/10.1017/S1474746419000101.

20. Lacey RE, Minnis H. Practitioner review: twenty years of research with adverse childhood experience scores - advantages, disadvantages and applications to practice. J Child Psychol Psychiatry. 2020;61 (2):116-30. https://doi.org/10.1111/jcpp.13135.

21. Hyatt M, Rodgers SE, Paranjothy S, Fone D, Lyons RA. The wales electronic cohort for children (WECC) study. Arch Dis Child - Fetal Neonatal Ed. 2011; 96(Suppl 1):Fa18.

22. Ford DV, Jones KH, Verplancke J-P, Lyons RA, John G, Brown G, et al. The SAIL Databank: building a national architecture for e-health research and evaluation. BMC Health Serv Res. 2009;9(1):157. https://doi.org/10.1186/14726963-9-157.

23. Lyons RA, Jones KH, John G, Brooks CJ, Verplancke J-P, Ford DV, et al. The SAIL databank: linking multiple health and social care datasets. BMC Med Inform Decis Mak. 2009;9(1):3. https://doi.org/10.1186/1472-6947-9-3.

24. Rodgers SE, Lyons RA, Dsilva R, Jones KH, Brooks CJ, Ford DV, et al. Residential Anonymous Linking Fields (RALFs): a novel information infrastructure to study the interaction between the environment and individuals' health. J Public Health Oxf Engl. 2009;31(4):582-8. https://doi. org/10.1093/pubmed/fdp041.

25. Rodgers SE, Demmler JC, Dsilva R, Lyons RA. Protecting health data privacy while using residence-based environment and demographic data. Health Place. 2012;18(2):209-17. https://doi.org/10.1016/j.healthplace.2011.09.006.

26. Evans A, Hardcastle K, Bandyopadhyay A, Farewell D, John A, Lyons RA, et al. Adverse childhood experiences during childhood and academic attainment at age 7 and 11 years: an electronic birth cohort study. Public Health. 2020;189:37-47. https://doi.org/10.1016/j.puhe.2020.08.027.

27. Lee JJ, Gonzalez-Izquierdo A, Gilbert R. Risk of maltreatment-related injury: a cross-sectional study of children under five years old admitted to hospital with a head or neck injury or fracture. PLoS One. 2012;7(10):e46522. https:// doi.org/10.1371/journal.pone.0046522.

28. Economou A, Grey M, McGregor J, Craddock N, Lyons RA, Owen MJ, et al. The health informatics cohort enhancement project (HICE): using routinely collected primary care data to identify people with a lifetime diagnosis of psychotic disorder. BMC Res Notes. 2012;5(1):95. https://doi.org/10.1186/1 756-0500-5-95

29. John A, McGregor J, Fone D, Dunstan F, Cornish R, Lyons RA, et al. Casefinding for common mental disorders of anxiety and depression in primary care: an external validation of routinely collected data. BMC Med Inform Decis Mak. 2016;16(1):35. https://doi.org/10.1186/s12911-016-0274-7.

30. Trefan L, Akbari A, Paranjothy S, Farewell DM, Gartner A, Fone D, et al. Electronic Longitudinal Alcohol Study in Communities (ELAStiC) Wales protocol for platform development. Int J Popul Data Sci. 2019;4(1) Available from: https://ijpds.org/article/view/581. Cited 2021 Mar 18.

31. Fone D, Morgan J, Fry R, Rodgers S, Orford S, Farewell D, et al. Change in alcohol outlet density and alcohol-related harm to population health (CHAL ICE): a comprehensive record-linked database study in Wales. Southampton: NIHR Journals Library; 2016. (Public Health Research). Available from: http:// www.ncbi.nlm.nih.gov/books/NBK350758/. Cited 2020 Dec 1

32. Mersky JP, Janczewski CE, Topitzes J. Rethinking the measurement of adversity: moving toward second-generation research on adverse childhood experiences. Child Maltreat. 2016;22(1):58-68. https://doi.org/10.1177/1 077559516679513

33. Greenland S, Pearl J, Robins JM. Causal diagrams for epidemiologic research. Epidemiol Camb Mass. 1999;10(1):37-48. https://doi.org/10.1097/00001648-1 99901000-00008.

34. Townsend P. Health and deprivation: inequality and the north. London: Routledge; 1989

35. StataCorp. Stata statistical software: release 15. College Station: StataCorp LLC; 2017.

36. White IR, Royston P, Wood AM. Multiple imputation using chained equations: issues and guidance for practice. Stat Med. 2011;30(4):377-99. https://doi.org/10.1002/sim.4067.
37. White IR, Royston P. Imputing missing covariate values for the Cox model. Stat Med. 2009;28(15):1982-98. https://doi.org/10.1002/sim.3618.

38. Haneuse S, VanderWeele TJ, Arterburn D. Using the E-value to assess the potential effect of unmeasured confounding in observational studies. JAMA. 2019;321(6):602-3. https://doi.org/10.1001/jama.2018.21554.

39. LaNoue MD, George BJ, Helitzer DL, Keith SW. Contrasting cumulative risk and multiple individual risk models of the relationship between adverse childhood experiences (ACEs) and adult health outcomes. BMC Med Res Methodol. 2020;20(1):239. https://doi.org/10.1186/s12874-020-01120-w.

40. Beardslee WR, Gladstone TRG, O'Connor EE. Transmission and prevention of mood disorders among children of affectively ill parents: a review. J Am Acad Child Adolesc Psychiatry. 2011;50(11):1098-109. https://doi.org/10.101 6/j.jaac.2011.07.020.

41. Weissman MM, Wolk S, Goldstein RB, Moreau D, Adams P, Greenwald S, et al. Depressed adolescents grown up. JAMA. 1999;281(18):1707-13. https://doi.org/10.1001/jama.281.18.1707.

42. Finan LJ, Schulz J, Gordon MS, Ohannessian CM. Parental problem drinking and adolescent externalizing behaviors: the mediating role of family functioning. J Adolesc. 2015;43:100-10. https://doi.org/10.1016/..a dolescence.2015.05.001.

43. Brook JS, Saar NS, Brook DW. Developmental pathways from parental substance use to childhood academic achievement. Am J Addict. 2010; 19(3):270-6. https://doi.org/10.1111/j.1521-0391.2010.00037.x.

44. Knudsen AK, Ystrom E, Skogen JC, Torgersen L. Maternal heavy alcohol use and toddler behavior problems: a fixed effects regression analysis. Eur Child Adolesc Psychiatry. 2015;24(10):1269-77. https://doi.org/10.1007/s00787-0150677-5.

45. Kuppens S, Moore SC, Gross V, Lowthian E, Siddaway AP. The enduring effects of parental alcohol, tobacco, and drug use on child well-being: a multilevel meta-analysis. Dev Psychopathol. 2020; 32(2): 765-778. https:// www.ncbinlm.nih.gov/pmc/articles/PMC7525110/.

46. Davis DW, Myers J, Logsdon MC, Bauer NS. The relationship among caregiver depressive symptoms, parenting behavior, and family-centered care. J Pediatr Health Care. 2016;30(2):121-32. https://doi.org/10.1016/j. pedhc.2015.06.004.

47. Smith M. Parental mental health: disruptions to parenting and outcomes for children. Child Fam Soc Work. 2004;9(1):3-11. https://doi.org/10.1111/j.13 65-2206.2004.00312.x.

48. Velleman $R$, Templeton $L$. Understanding and modifying the impact of parents' substance misuse on children. Adv Psychiatr Treat. 2007;13(2):7989. https://doi.org/10.1192/apt.bp.106.002386.

49. Velleman $R$, Templeton $L$. Impact of parents' substance misuse on children: an update. BJPsych Adv. 2016;22(2):108-17. https://doi.org/10.1192/apt. bp.114.014449.

50. Cosgaya L, Nolte M, Martínez-Pampliega A, Sanz M, Iraurgi I. Interparental conflict, parent-child relationships and emotional impact on children. Int J Soc Psychol. 2008;23(1):29-40. https://doi.org/10.1174/021347408783399561.

51. Smith JAS, Adler RG. Children hospitalized with child abuse and neglect: a case-control study. Child Abuse Negl. 1991;15(4):437-45. https://doi.org/10.1 016/0145-2134(91)90027-B.

52. Nelson EC, Heath AC, Madden PAF, Cooper ML, Dinwiddie SH, Bucholz KK, et al. Association between self-reported childhood sexual abuse and adverse psychosocial outcomes: results from a twin study. Arch Gen Psychiatry. 2002;59(2):139-45. https://doi.org/10.1001/archpsyc.59.2.139.

53. Norman RE, Byambaa M, De R, Butchart A, Scott J, Vos T. The long-term health consequences of child physical abuse, emotional abuse, and neglect: a systematic review and meta-analysis. PLoS Med. 2012;9(11):e1001349. https://doi.org/10.1371/journal.pmed.1001349.

54. Thoresen S, Myhre M, Wentzel-Larsen T, Aakvaag HF, Hjemdal OK. Violence against children, later victimisation, and mental health: a cross-sectional study of the general Norwegian population. Eur J Psychotraumatology. 2015;6(1):26259. https://doi.org/10.3402/ejpt.v6.26259.

55. World Health Organisation. Gender disparities in mental health. 2020. Available from: https://www.who.int/mental_health/prevention/ genderwomen/en/. Cited 2020 Oct 16.

56. Williams GM, O'Callaghan M, Najman JM, Bor W, Andersen MJ, et al. Maternal cigarette smoking and child psychiatric morbidity: a longitudinal study. Pediatrics. 1998;102(1):e11. https://doi.org/10.1542/peds.102.1.e11.

57. Höök B, Cederblad M, Berg R. Prenatal and postnatal maternal smoking as risk factors for preschool children's mental health. Acta Paediatr. 2006;95(6): 671-7. https://doi.org/10.1080/08035250500538965. 
58. Font SA, Maguire-Jack K. Pathways from childhood abuse and other adversities to adult health risks: the role of adult socioeconomic conditions. Child Abuse Negl. 2016;51:390-9. https://doi.org/10.1016/j.chiabu.2015.05. 013.

59. Straatmann VS, Lai E, Law C, Whitehead M, Strandberg-Larsen K, TaylorRobinson D. How do early-life adverse childhood experiences mediate the relationship between childhood socioeconomic conditions and adolescent health outcomes in the UK? J Epidemiol Community Health. 2020;74(11): 969-75. https://doi.org/10.1136/jech-2020-213817.

60. Widom CS, Raphael KG, DuMont KA. The case for prospective longitudinal studies in child maltreatment research: commentary on Dube, Williamson, Thompson, Felitti, and Anda (2004). Child Abuse Negl. 2004;28(7):715-22. https://doi.org/10.1016/j.chiabu.2004.03.009.

61. Anthony RE, Paine AL, Shelton KH. Adverse childhood experiences of children adopted from care: the importance of adoptive parental warmth for future child adjustment. Int J Environ Res Public Health. 2019;16(12): 2212.

62. Hinrichs S, Owens M, Dunn V, Goodyer I. General practitioner experience and perception of Child and Adolescent Mental Health Services (CAMHS) care pathways: a multimethod research study. BMJ Open. 2012;2(6):e001573. https://doi.org/10.1136/bmjopen-2012-001573.

63. Scott D, Tonmyr L, Fraser J, Walker S, McKenzie K. The utility and challenges of using ICD codes in child maltreatment research: a review of existing literature. Child Abuse Negl. 2009;33(11):791-808. https://doi.org/10.1016/j. chiabu.2009.08.005.

64. Burke DA, Koot HM, de Wilde A, Begeer S. Influence of child factors on health-care professionals' recognition of common childhood mental-health problems. J Child Fam Stud. 2016;25(10):3083-96. https://doi.org/10.1007/s1 0826-016-0475-9.

65. Afifi TO. Chapter 3 - considerations for expanding the definition of ACEs. In: Asmundson GJG, Afifi TO, editors. Adverse childhood experiences: Academic; 2020. p. 35-44. Available from: https://www.sciencedirect.com/ science/article/pii/B9780128160657000033. Cited 2021 Mar 18.

66. Hernán MA. The hazards of hazard ratios. Epidemiol Camb Mass. 2010;21(1): 13-5. https://doi.org/10.1097/EDE.0b013e3181c1 ea43.

67. Bethell C, Jones J, Gombojav N, Linkenbach J, Sege R. Positive childhood experiences and adult mental and relational health in a statewide sample: associations across adverse childhood experiences levels. JAMA Pediatr. 2019;173(11):e193007. https://doi.org/10.1001/jamapediatrics.2019.3007.

68. Taylor-Robinson DC, Straatmann VS, Whitehead M. Adverse childhood experiences or adverse childhood socioeconomic conditions? Lancet Public Health. 2018;3(6):e262-3. https://doi.org/10.1016/S2468-2667(18)30094-X.

69. Ellis WR, Dietz WH. A new framework for addressing adverse childhood and community experiences: the building community resilience model. Acad Pediatr. 2017;17(7):S86-93. https://doi.org/10.1016/j.acap.2016.12.011.

70. Baldwin JR, Caspi A, Meehan AJ, Ambler A, Arseneault L, Fisher $\mathrm{HL}$, et al. Population vs individual prediction of poor health from results of adverse childhood experiences screening. JAMA Pediatr. 2021;175(4):385-93. https:// doi.org/10.1001/jamapediatrics.2020.5602.

\section{Publisher's Note}

Springer Nature remains neutral with regard to jurisdictional claims in published maps and institutional affiliations. 